\title{
Renal Clearance to Total Clearance Ratio Measurement After Intravenous Dosing
}

National Cancer Institute

\section{Source}

National Cancer Institute. Renal Clearance to Total Clearance Ratio Measurement After

Intravenous Dosing. NCI Thesaurus. Code C154850.

The portion of total clearance attributed to the kidneys expressed as a percentage, following an intravenous dosing. 